\title{
Operation of an Aluminum-Intensive Vehicle: Report on a Six-Year Project
}

\author{
Linda Gaines and Roy Cuenca \\ Center for Transportation Research, Argonne National Laboratory
}

\begin{abstract}
In 1994, Ford produced a small demonstration fleet of Mercury Sables with aluminum bodies. Argonne National Laboratory obtained one of these vehicles on a lease so that Laboratory staff could observe the wear characteristics of the body under normal operating conditions. The vehicle was placed in the transportation pool, parked outdoors, and used by staff members for both local and longer trips. The vehicle performed normally, except for having particularly good acceleration because of its light weight and highpower SHO engine. No significant problems were encountered that related to the Al body or engine. No special driving protocols were observed, but a log was kept of trip lengths and fuel purchases. Fuel economy was observed to be improved, compared with that of a similar conventional steel-bodied vehicle that was available for one year of the lease period. The vehicle was tested on a chassis dynamometer to obtain emissions and fuel economy over the federal test cycle. The impacts of further mass reduction were also simulated. At the end of the lease, the body was in excellent condition, which we documented with a set of detailed photographs before the vehicle was returned to Ford. There were minor imperfections in the painted surface, probably resulting from the omission of an E-coat during the painting process. We also examined three similar conventional vehicles for comparison; these exhibited varying degrees of rust.
\end{abstract}

\section{INTRODUCTION}

U.S. automobile fuel economy, adjusted for vehicle size, has improved markedly since the two oil price shocks of the 1970s. Technologies responsible for improved fuel economy include fuel injection, front-wheel drive, improved engine aspiration (multi-valves/cylinder, turbo- and supercharging), transmission technologies (e.g., four-speed automatic with lock-up), improved aerodynamics, tires with lower rolling resistance, and increased use of lightweight materials. While many of these measures have already been used in production vehicles, the only area besides totally new power plants and hybridization that promises significant improvements in fuel economy in the future is the use of lightweight materials for body and chassis components.
If Corporate Average Fuel Economy (CAFE) standards are raised, or if oil prices rise sharply over an extended period, automakers will be faced with the need to further reduce vehicle weight. Downsizing is one option, but automakers are keenly interested in cost-effective, lightweight materials to reduce vehicle weight without sacrificing vehicle utility.

The desire to increase the fuel economy of a vehicle creates a significant motivation for reducing its curb (empty) weight. There are at least three ways to decrease the empty weight of a vehicle: (1) reduce its size, (2) optimize its design to minimize weight, and (3) replace the materials used in its construction with lighter mass equivalents. The third alternative, use of lightweight materials, has been pursued to some extent, but greater gains are possible. This paper describes operating experience with the aluminum-bodied Mercury Sable developed by Ford, the result of a pure substitution exercise. In addition to taking advantage of the lighter mass of aluminum compared with steel, further weight reduction is possible through parts integration and "holistic" design approaches. The impact of weight reduction on life cycle energy is discussed. Although several studies have examined corrosion of aluminum body panels in the laboratory or recovered from junkyards [1-3], we are not aware of any previous studies of individual vehicle operation.

\section{DESCRIPTION OF THE VEHICLE}

Prototype aluminum-intensive vehicles (AIVs) based on mass-produced versions have been developed by most automakers. One of the best-documented examples is the aluminum-body Mercury Sable. The vehicle was part of a design and production study aimed at evaluating the feasibility of a stamped-aluminum body process for mass manufacture of passenger cars [4]. The Sable AIV was described in detail by Cornille [5]. The approach was to replace the material (i.e., use aluminum-alloy sheet instead of steel), while maintaining the current vehicle design (1993 Sable) and using essentially the same body-manufacturing process (spot welding and bonded sheet-metal stampings). The only differences were that the AIV body was specially manufactured with low-volume tooling (as in a prototype) and adhesive bonding was combined with the welding process. The actual AIV Sable used a powertrain similar 
to that of the Taurus SHO; that powertrain was chosen because it has a mostly aluminum engine. The $\mathrm{SHO}$ powertrain is actually slightly heavier than the standard because it was designed for higher performance $(220 \mathrm{hp}$ vs. 140 for the standard). The engine is larger and more powerful, but most of the mass increase is for larger components, such as the radiator and brakes, to accommodate the greater heat load and forces. Note in Table 1 that, although the Taurus SHO is considerably heavier than the standard Taurus, the AIV is still lighter than the conventional vehicle.

Table 11994 Vehicle Masses (CV data from [6])

\begin{tabular}{|l|c|c|}
\hline Model & Mass $(\mathbf{l b})$ & Mass $\mathbf{( k g})$ \\
\hline Taurus 4-door & 3,104 & 1,408 \\
\hline Taurus SHO 4-door & 3,395 & 1,540 \\
\hline Sable 4-door & 3,126 & 1,418 \\
\hline Sable AIV & 3,035 & 1,377 \\
\hline
\end{tabular}

The mass reduction achieved for the body was $173 \mathrm{~kg}$ (380 lb); about $47 \%$ less than the equivalent steel body. A comparison of the mass of individual key components as produced by using both materials is shown in Table 2 [5]. In addition to the mass saved with the aluminum body, other changes in the powertrain and chassis (allowed by the lower mass of the body) could have resulted in a further reduction of about $90 \mathrm{~kg}(200 \mathrm{lb})$, for a total mass reduction of about $20 \%$ compared with the standard steel-intensive Sable. Therefore, use of aluminum for the body plus secondary weight savings could turn a $1,418-\mathrm{kg}(3,126 \mathrm{lb})$, four-door, mid-size sedan into a 1,155-kg-curb-weight $(2,546 \mathrm{lb})$ vehicle.

\section{VEHICLE USE AND SERVICE EXPERIENCE}

We first drove the AIV on September 8, 1994, with the odometer reading 219 miles. The vehicle was parked outside and used by Argonne staff for two types of official work-related trips: very short trips on the Laboratory site, and medium-distance road trips, usually not exceeding 300 miles. The longest trip, from Argonne to Washington, D.C., was about 750 miles each way. The climate in the Chicago area is hard on cars, with freeze-thaw cycles and salt usage in winter, and hot, humid summers. Operation of the car resembled that of a businessman's vehicle, with predominantly short, local trips and occasional out-of-town trips, rather than that of a commuter car, which repeats the same trip many times. The number of trips and the accumulation of miles were seasonal, both decreasing sharply in the winter and the middle of the summer (vacation time). The vehicle accumulated 15,650 miles on its first year, close to the national average for cars of similar age. It averaged about 12 miles per trip, with a combination of numerous short trips and many longer trips (over 200 miles). Passenger load was a modest 1.5 passengers/trip [7]. The number of miles per year decreased sharply in the last 2 years of the lease, as can be seen in Table 4. The last trip we took in the AIV was logged out at 67,222 miles on October 16, 2000, after six years and one month of use.

There were no restrictions on vehicle users; it was available to all ANL staff with an official need to travel. Since the body was lighter and the SHO powertrain was far more powerful than the standard Sable/Taurus, the vehicle was extremely responsive and fast. Therefore, it was very popular. It was serviced regularly by Argonne's garage, and washed every week or two. The aluminum body introduced no special operational problems during the six years of operation. There was no structural failure of any aluminum part, and no body noise or rattles developed. None of the problems experienced with the vehicle were related to the aluminum components, and most were typical minor vehicle operating problems. There were two fluid leaks: one in the coolant (a hose was replaced) and another in the power steering system (the power steering rack required

Table 2 Comparison of Steel and Aluminum Mercury Sable Body

\begin{tabular}{|l|c|r|r|r|r|r|r|}
\hline & & \multicolumn{2}{|c|}{ Steel Mass (kg) } & \multicolumn{2}{c|}{$\begin{array}{c}\text { Aluminum Mass } \\
(\mathbf{k g})\end{array}$} & \multicolumn{2}{c|}{ Saving } \\
\hline Component & Number & Each & Total & Each & Total & kg & $\%$ Mass \\
\hline Fenders & 2 & 3.2 & 6.4 & 1.4 & 2.8 & 3.6 & 57 \\
\hline Decklid & 1 & 17 & 17 & 5.4 & 5.4 & 6.6 & 55 \\
\hline Hood & 1 & 22.2 & 22.2 & 9.1 & 9.1 & 13.2 & 59 \\
\hline Front door & 2 & 17 & 34 & 9.8 & 19.6 & 14.5 & 43 \\
\hline Rear door & 2 & 12.9 & 25.8 & 8.2 & 16.4 & 9.5 & 37 \\
\hline Unit body & 1 & 270.3 & 270.3 & 145 & 145 & 125.2 & 46 \\
\hline Total & & & 371 & & 198 & 173 & 47 \\
\hline
\end{tabular}


replacement twice* ${ }^{*}$. There was a dead battery and a vapor lock in extreme heat. There were several minor electrical failures involving the radio and the heater, and various hoses and screws had to be tightened when they became loose. There were two minor scratches in the plastic fascia of the rear bumper that resulted from a low-speed collision, but no damage was done to the Al body.

The fuel consumed by the AIV was measured at the delivery pump in the usual way; no special instrumentation was installed. The vehicle was refueled at the central Argonne depot or at commercial stations off-site. The drivers were requested to document fuel inputs and odometer readings on log sheets when they refueled.

\section{BODY CONDITION}

Before sending the AIV back to Ford at the end of the lease, we documented the condition of the body. We had the car washed, examined the body carefully, and had a professional photographer take a detailed set of photographs. These included views of the entire car from all sides, close-ups of all imperfections, and area views to record their locations. From the views of the entire vehicle (e.g., see Figure 1), it was apparent that the AIV still looked essentially new when we sent it back after six years of use.

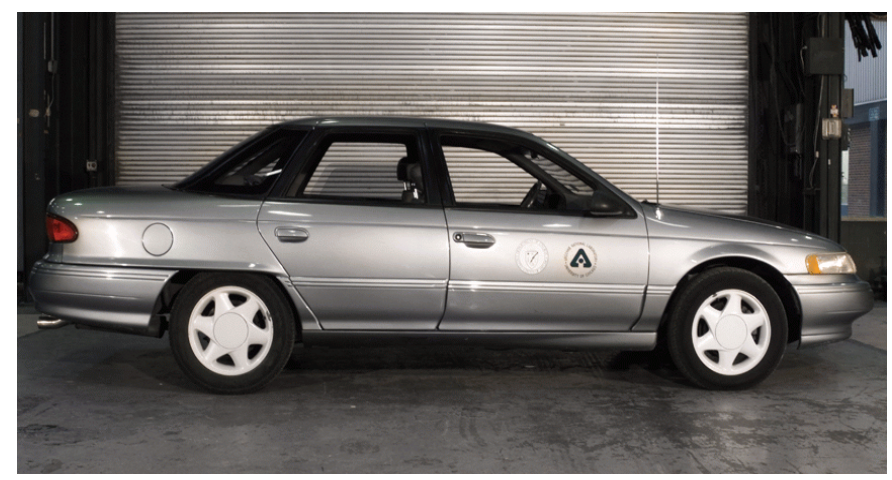

Figure 1 AIV after 6 Years of Use

The finish was still smooth and shiny and the color was still true. No change in shape could be observed. Similarly, the engine looked new, with no signs of corrosion. On closer inspection, some minor imperfections in the finish were observed and recorded; these are discussed here.

The imperfections were of several types, including chipped paint, blisters, scratches, dings, and poor paint coverage. There was, as expected, no rust or other type of corrosion, even on uncoated surfaces. Several photos show areas

* It is possible that this part was not designed to handle the forces generated by the more powerful engine. where rust often occurs on conventional vehicles (e.g., the interior of the driver's door and sill) to be shiny and newlooking. The vehicle had not been involved in any accidents (other than the low-speed collision that slightly damaged the bumper). Although this was fortunate in some ways, it also meant that there were no large dents, scratches, or other types of damage to observe and repair. Therefore, we obtained no information on the behavior of the body under severe stress conditions. Note also that safety testing and analysis were beyond the scope of our project, which was simply to test-drive the vehicle under normal conditions.

There were several places where small areas of paint had chipped off. These included one on the driver's door handle, one on the top corner of the left passenger door, and one on the edge of the right rear door (see Figure 2). In each case, the chip occurred in an area likely to have hit something when a door was opened. Several layers of the finish had chipped off (in some cases down to the substrate), but no corrosion resulted. There were a few small scratches and scrapes where one or more layers of paint had been removed, presumably by interaction with some external object. No further deterioration was observed at these sites. These imperfections were seen near the top of the driver's door panel, on the left rear passenger door and right rear door, on the deck lid, at the back of the roof, and near the gas cap.

The imperfections identified so far all are likely to have resulted from impacts with something outside of the vehicle. In addition, however, there were minor imperfections in the finish that appeared to be the results of problems with adherence of the paint to the aluminum substrate. Consultation with Ford [8] revealed that the

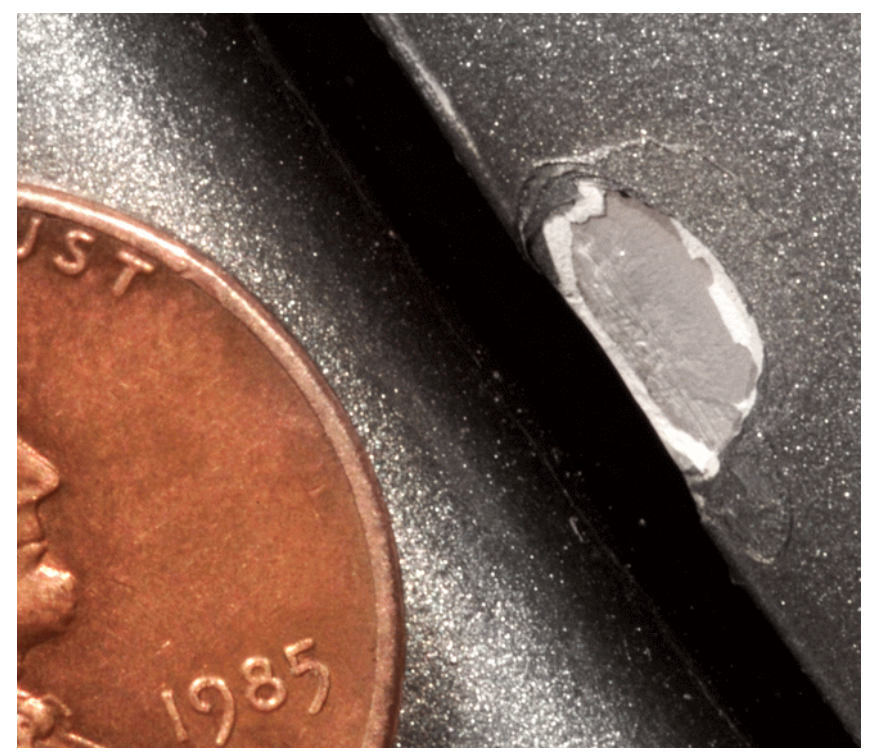

Figure 2 Paint Chipped Off on Door Edge 
vehicle had not received an E-coat prior to painting (for logistical reasons). This explains the minor paint adhesion problems, which do not occur in mass-produced $\mathrm{Al}$ closures.

In one case, the paint was only thinly covering the substrate when we examined the car. This was on the left C-pillar, and it was the black trim paint rather than the silver body paint. There were many places on the vehicle that showed minor blistering or dimpling. Note that some of these could conceivably have been caused by deterioration of the substrate, but it was impossible to tell without destructive testing. There were a few small $(<1 / 8$ in.) dimples on the left quarter panel just under the window and on the roof near the left rear door. There were many instances of blistering; most of the imperfections found were in this category. There were clusters of small blisters, mostly on pillars, and single blisters, most of which had popped (although some of the spots we identified as popped blisters could have been caused by external impacts). Some clusters of blisters occurred on the corners of closures, but most were in the black-painted pillar areas. There was a small cluster at the right corner of the trunk, another by the bottom of the right A-pillar, and several larger ones on right B-pillar. There was only one unpopped single blister, which was by the upper corner of the right front door. Popped blisters were observed on the left Apillar, just over the rear view mirror, on the roof near the left rear door, in the center of the left rear door, and in numerous locations on the hood. All of the popped blisters resulted in loss of the top coat of paint only, consistent with a problem with the paint rather than the substrate. We were not authorized to perform any destructive testing and so could not examine these defects further.

\section{COMPARISON WITH CONVENTIONAL VEHICLE BODIES}

For comparison, we identified three comparable conventional 1994 Taurus or Sable vehicles that were available and owned by staff members at ANL. All were the original owners, who graciously allowed us to examine their vehicles. We photographed the imperfections of the finishes on these vehicles as well (but not as painstakingly). All of the bodies were in good condition, but there was some rust observed, even though the vehicles had been garaged. Characteristics of these vehicles are summarized in Table 3. We recognize that there were not enough vehicles for our results to be statistically meaningful, and this was certainly not a controlled experiment, but our observations are nonetheless suggestive and instructive.

Vehicle 1: Very few imperfections were found on the body surface of this car. There were a few minor dings on the hood, where a spot of paint had chipped off. A small amount of rust was observed in the center of the largest of these. There was minor blistering of the paint on the window frame and a small amount of rust on the inside of some of the doors. No body rust or engine compartment corrosion (except on the bolts) was observed.

Vehicle 2: This vehicle had very little rust; the only place we found any was around a cutout on the inside of the hatch. There were minor dents, but these were not rusty. The car had required no body work, but had developed transmission, suspension, and tire problems.

Vehicle 3: This vehicle had significant rust on the inside of the driver's door, which had been damaged in an accident

Table 3 Conventional Vehicle Characteristics Summary

\begin{tabular}{|l|l|l|l|}
\hline & \multicolumn{1}{|c|}{ Vehicle 1 } & \multicolumn{1}{c|}{ Vehicle 2 } & \multicolumn{1}{c|}{ Vehicle 3 } \\
\hline Model & Taurus sedan & Taurus station wagon & Sable sedan \\
\hline Color & green & red & light blue \\
\hline Trips & $\begin{array}{l}<20 \text { mi plus annual } \\
500 \text { mi vacation }\end{array}$ & $\begin{array}{l}<20 \text { mi except annual } \\
\text { vacation }\end{array}$ & $\begin{array}{l}\text { short trips: } \\
\text { local, commuting, and freeway }\end{array}$ \\
\hline Total miles & 110,000 & 103,000 & 70,000 \\
\hline $\begin{array}{l}\text { Fuel economy } \\
\text { (mpg) }\end{array}$ & 22 & 19 city $^{\text {a }, 30 ~ h i g h w a y ~}$ & $22-23$ when new \\
\hline Fuel & regular unleaded & regular unleaded & regular unleaded \\
\hline Accidents? & No & No & Yes \\
\hline Garaged & Until last $\sim 2 \mathrm{yr}$ & Yes & Yes \\
\hline Body Condition & Good & Minimal rust & Some rust, blistering paint \\
\hline
\end{tabular}

${ }^{a}$ First driver consistently achieved $19 \mathrm{mpg}$. More recent driver accelerates more slowly and achieves 20-21 mpg. 
and repaired (see Figure 3 ). In addition, blistering was observed in the paint on the window frame.

Several general conclusions can be drawn from our examination of these conventional vehicles. The first is that, while the CVs did not look as good after six years as the AIV, all the bodies were still quite functional, with no major rust and no apparent deterioration. There was some tendency to show visible rust, especially on the insides of the doors, and blisters on the window frames could indicate rust under the paint. No dimples or popped blisters like those on the AIV were observed on the conventional vehicles. Note that this evaluation was done on six-year-old cars; it is quite possible that vehicles showing minor rust at six could have serious structural problems before they reach the ends of their useful lives. Note also that the fuel economy of the steel-bodied cars ( $22 \mathrm{mpg}$ ) was about the same as that of the AIV, in spite of the more powerful SHO powertrain in the AIV. Vehicle masses were similar.

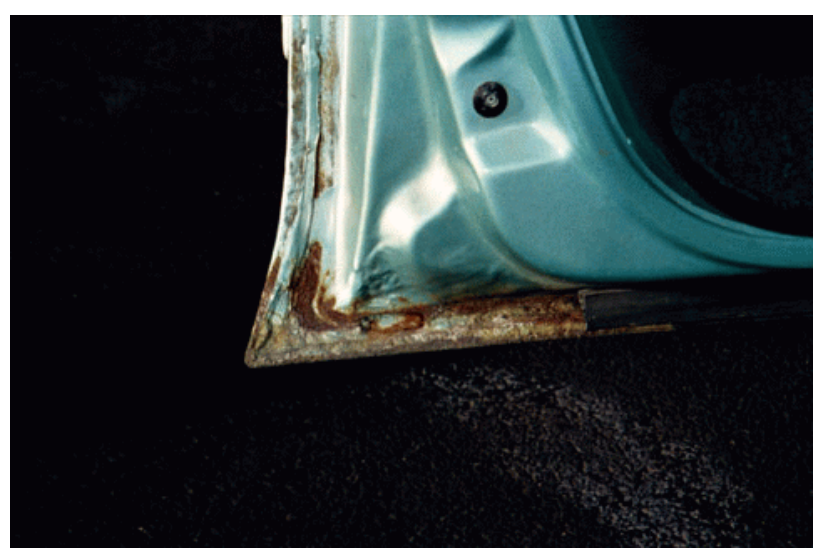

Figure 3 Rust on Conventional Vehicle Door

\section{DYNAMOMETER TESTING}

The car was tested on a chassis dynamometer according to the Federal Test Procedure (FTP) to obtain an estimate of the fuel economy and emissions comparable with that published by the United States Environmental Protection Agency. Two different tests were conducted, with standard inertial test weights of $3,375 \mathrm{lb}(1,507 \mathrm{~kg}$ - as close as possible to the normal test weight of a Taurus SHO production vehicle) and $2,750 \mathrm{lb}(1,248 \mathrm{~kg})$. While the actual weight reduction in the AIV Sable was only about $400 \mathrm{lb}(181 \mathrm{~kg})$, the lower mass was chosen to include the potential effect of secondary weight savings. (For every pound of direct mass reduction, it is generally possible to save another $0.5 \mathrm{lb}$ by downsizing such components as brakes, engine, springs, etc.). Tailpipe emissions were measured and fuel consumption calculated via a carbon balance. The results (average of two tests) are shown in Table 4.

The fuel economy advantage of the simulated $18.5 \%$ lighter vehicle was estimated to be $6 \%$ in the city test and $3 \%$ in the highway test. This can be compared with improvements of $14 \%$ city and $10 \%$ highway predicted for these test masses by an engineering model [9], with parameters based on a statistical treatment of over 100 typical conventional vehicles. However, the AIV was very atypical, effectively set up as a high-performance car (powerful engine, lightweight body), with a powertrain that had not been optimized to be most efficient at the reduced mass (e.g., by downsizing so that acceleration performance would be equivalent to the heavier Taurus). The SHO engine power density and the AIV power-toweight ratio were far greater than those of the typical vehicle in the statistical sample. This single result suggests that body mass reduction alone in a vehicle with a very powerful drivetrain may not be very effective.

Table 4 Dynamometer Test Results (emissions in $\mathrm{g} / \mathrm{mi}[\mathrm{g} / \mathrm{km}]$ )

\begin{tabular}{|c|c|c|c|c|c|c|c|c|}
\hline \multirow{2}{*}{$\begin{array}{l}\text { Inertial Test } \\
\text { Weight (lb) } \\
\text { [kg] }\end{array}$} & \multicolumn{4}{|c|}{ City } & \multicolumn{4}{|c|}{ Highway } \\
\hline & $\mathrm{mpg}[\mathrm{km} / \mathrm{l}]$ & THC & $\mathrm{CO}$ & $\mathrm{NO}_{\mathrm{x}}$ & $\mathrm{mpg}[\mathrm{km} / \mathrm{l}]$ & THC & $\mathrm{CO}$ & $\mathrm{NO}_{\mathrm{x}}$ \\
\hline $\begin{array}{l}3,375 \\
{[1,507]}\end{array}$ & $\begin{array}{l}19.41 \\
{[8.24]}\end{array}$ & $\begin{array}{c}0.26 \\
{[0.16]}\end{array}$ & $\begin{array}{c}1.73 \\
{[1.08]}\end{array}$ & $\begin{array}{c}0.23 \\
{[0.14]}\end{array}$ & $\begin{array}{c}34.10 \\
{[14.48]}\end{array}$ & $\begin{array}{c}0.11 \\
{[0.066]}\end{array}$ & $\begin{array}{c}0.66 \\
{[0.41]}\end{array}$ & $\begin{array}{c}0.58 \\
{[0.036]}\end{array}$ \\
\hline $\begin{array}{l}2,750 \\
{[1,248]}\end{array}$ & $\begin{array}{l}20.54 \\
{[8.72]}\end{array}$ & $\begin{array}{c}0.24 \\
{[0.15]}\end{array}$ & $\begin{array}{c}1.65 \\
{[1.03]}\end{array}$ & $\begin{array}{c}0.23 \\
{[0.14]}\end{array}$ & $\begin{array}{c}35.03 \\
{[14.86]}\end{array}$ & $\begin{array}{c}0.10 \\
{[0.064]}\end{array}$ & $\begin{array}{c}0.64 \\
{[0.40]}\end{array}$ & $\begin{array}{c}0.50 \\
{[0.030]}\end{array}$ \\
\hline $\begin{array}{l}\text { Percent } \\
\text { improvement }\end{array}$ & 5.8 & 9.1 & 4.5 & 1.7 & 2.7 & 2.8 & 2.6 & 14.7 \\
\hline
\end{tabular}




\section{FUEL ECONOMY RESULTS}

Although measurement of fuel economy was not included in the scope of our project, we did attempt to keep records because of the general interest in the topic. However, because essentially anyone could drive the vehicle, refueling information was not always reliably recorded. Therefore, data analysis required removal of points that showed apparent unrealistically high mileage because of missing fuel data. In addition, there was probably considerable variation among the acceleration patterns of different drivers and in how full they got the tank. These factors account for some of the variations observed in the refueling data (see Figure 4, which has outliers removed); further variation can be explained by differences associated with season and trip length.

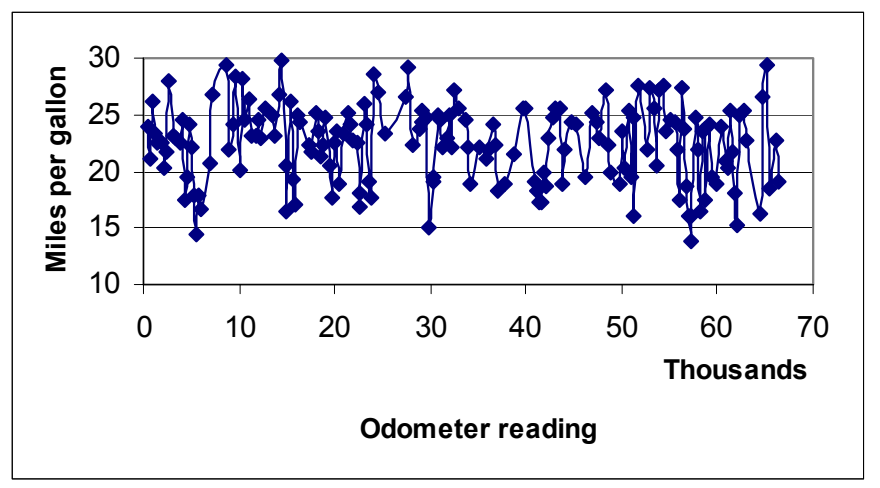

Figure 4 Trip MPG vs. Odometer Reading

Another confounding factor affecting the fuel efficiency was the fuel type used. The SHO powertrain was designed to use high-octane fuel, but also functioned well with regular (the engine sensed pre-ignition and retarded the timing). There was no noticeable difference in the sound, power level, acceleration, or any other vital sign when operating with either fuel. Because the Argonne fuel depot did not carry high-octane gasoline, it was decided to use regular (87 octane) unleaded gasoline. However, when out on the road, many drivers preferred to purchase high-octane gasoline (at commercial stations). Therefore, there was some mixing of the two fuels in the early years. Analysis of the limited data suggests that the vehicle was probably more efficient with high-octane fuel. However, use of premium fuel was correlated with longer off-site trips, which is more likely to account for the improvement. Longer trips tended to be at highway speeds and yield higher fuel efficiency, as can be seen in Figure 5. These are data for the first fall of operation, so there should be no seasonal variations confounding the trend. Since most fuelings were for a mixture of long and short trips, the $\mathrm{X}$-axis for the graph is number of miles between fill-ups that were on trips over 50 miles. The fuel efficiency also seemed to be

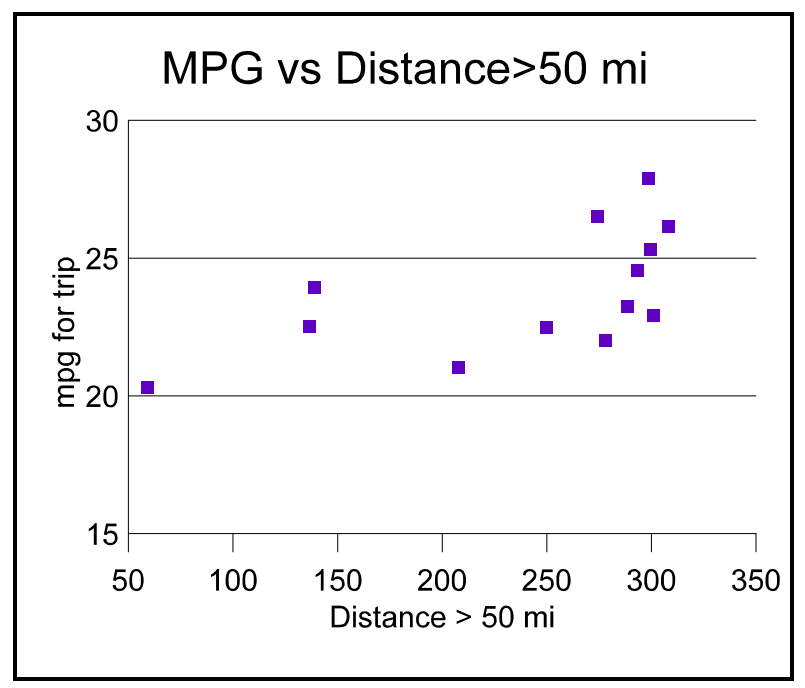

Figure 5 Fuel Economy vs. Trip Length

seasonal, decreasing during the winter and peaking during the spring, as can be seen in Figure 6. The reason was probably a combination of low ambient temperature and trip length, which tended to be particularly short in the winter. Fuel efficiency did not change significantly over the test period, as can be seen in Table 5 .

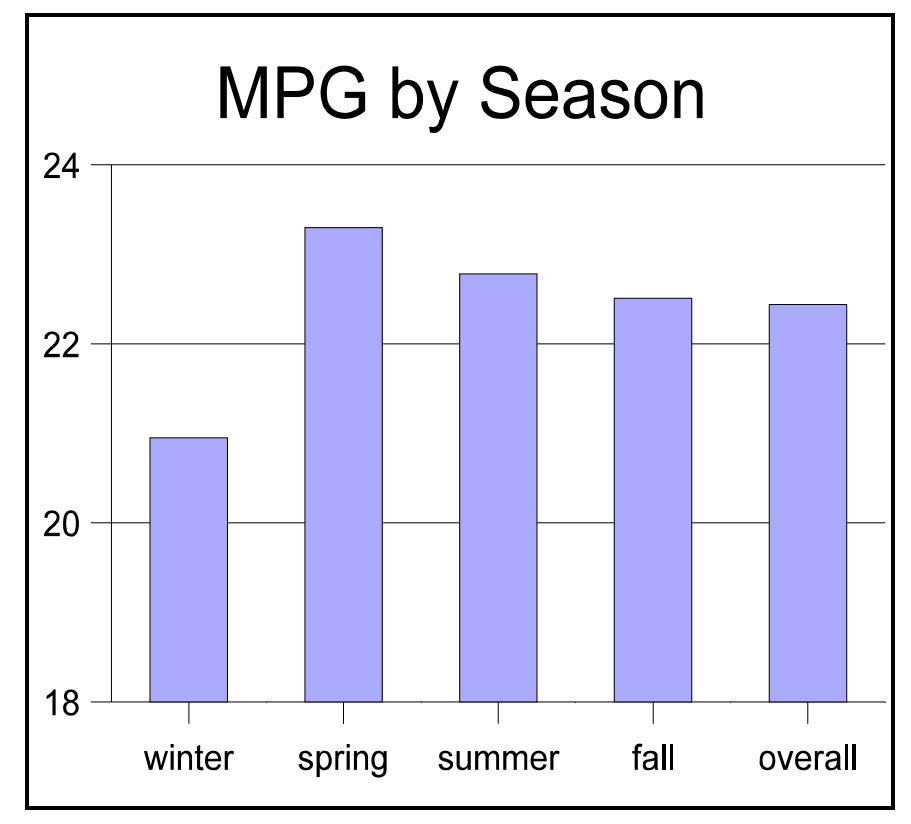

Figure 4 Seasonal Variation of AIV Fuel Economy 
Table 5 AIV Use and Fuel Economy

\begin{tabular}{|l|l|l|}
\hline Year & miles & \multicolumn{1}{c|}{ mpg } \\
\hline 1 & 15,649 & 23.0 \\
2 & 14,348 & 22.6 \\
3 & 11,838 & 21.9 \\
4 & 14,181 & 23.1 \\
5 & 4,297 & 20.5 \\
6 & 6,189 & 22.0 \\
Overall & 67,222 & 22.4 \\
\hline
\end{tabular}

Although the low mass of the AIV was expected to improve fuel economy, the more powerful SHO powertrain and its associated larger components were expected to offset some of the gain. Therefore, the vehicle could not be directly compared with a standard Taurus/Sable, but rather needed to be compared to the Taurus SHO, a much less common vehicle. Funds were not available for lease of a control vehicle, especially since fuel economy testing was secondary to our mission in this project. A close alternative was conveniently available in the personal vehicle of a CTR staff member. His car was not identical, as it was an older SHO model (1989) with manual transmission, but it was operated in the same geographic location, and fuel consumption records were available. The conventional Taurus SHO was operated as a commuter car and took fewer very short and very long trips than the AIV. It was driven fewer miles, with a single driver, and operated exclusively on premium fuel. These differences imply that results should only be considered suggestive. Controlled tests would be required before drawing quantitative conclusions.

Only one year of comparison data were obtained for the Taurus (which was then 5 years old) because the owner sold it. Overall fuel economy of the AIV $(22 \mathrm{mpg})$ was observed to be $12 \%$ better than that $(20 \mathrm{mpg})$ obtained with a steel-body Taurus SHO. This is far in excess of the value suggested by the dynamometer tests. It is also larger, but less so, than estimates based on empirical and physics-based simulation studies of the average effects of mass on fuel economy. [9-11] (These imply $8 \%$ improvement for the city cycle and $6 \%$ for the highway cycle, for the actual vehicle masses.) In summary, our attempts to delineate the effects of mass on fuel economy by three different approaches all imply improved fuel economy with reduced mass. However, the results were highly variable, with those from dynamometer tests lower and actual field data higher than model calculations, which are probably closest to reality.

\section{IMPLICATIONS FOR LIFE CYCLE ANALYSIS}

Although the initial rationale for light-weighting was to save fuel during vehicle operation, some analysts were concerned that the fuel economy gains might be offset by the higher initial energy requirements for production of aluminum compared to steel. Production of aluminum parts is energy intensive, but can be reduced by about $75 \%$ by using recycled materials. Initial analyses of aluminumintensive vehicles showed a payback in net energy use after a large number of miles, in some cases more than expected vehicle life (e.g.,[12]), but these studies generally did not consider use of recycled materials. Numerous analyses were also published for specific parts. It was unclear how much energy and in what form would be saved by using aluminum in vehicles.

Therefore, we undertook an analysis of the AIV in 1995, based on previously published fuel-economy improvement estimates, and found that the primary energy embodied in the vehicle materials and manufacturing process was small relative to the fuel energy consumed by the vehicle, both for individual vehicles and fleets [13]. Costs were also discussed. The primary energy embodied in the vehicle materials and manufacturing process (vehicle cycle) was found to range between $8 \%$ (with recycling) and $12 \%$ (without recycling) of the total primary energy consumed over the lifetime of the vehicle. We estimated the energy payback to occur after the AIV was driven about 60,000 miles, but use of recycled material reduced the number of miles. In fact, maximum recycling could reduce the AIV production energy to below that of a conventional steel vehicle because recycled Al parts are less energy-intensive than steel parts. Compared with recycling other widely used vehicle materials, recycling wrought aluminum back to wrought aluminum saved the most energy. Over the AIV life cycle, far more oil was saved than such other fuels as coal, natural gas, and non-fossil fuels.

If, indeed, the mileage improvement from light-weighting a vehicle were greater than the $0.66 \%$ per percent weight reduction we assumed in our 1995 paper, then the usephase energy consumption would be lower and the material and manufacturing percentage contribution higher. The extra energy saved could be as great as the vehicle cycle energy (with recycling) and all in the form of petroleum.

Our study compared aluminum-intensive vehicles with conventional steel vehicles (see [13] for a discussion of the materials). The Al vs. steel controversy revived as a result of the 1998 introduction of the ultralight steel auto body (ULSAB) and the subsequent analysis by Massachusetts 
Institute of Technology (MIT), which was presented at a press conference at a meeting of the American Iron and Steel Institute (AISI) [14]. The presentation showed that a fleet of AIVs took about 40 years to pay back its production energy deficit. Unfortunately, the unpublished results were both flawed and excerpted in a biased way, emphasizing comparison with the ULSAB, not in mass production, and neglecting to show the large payback that would eventually occur. In addition, some of the input numbers were incorrect, and little or no aluminum recycling was assumed. Although MIT later corrected their calculations [15], the press had a field day. "Study crushes idea for aluminum vehicle" was one headline [16]. In response, the Aluminum Association published an excellent and complete life-cycle analysis of the production of fabricated aluminum products [17]. The steel industry also produced a fine analysis [18], but limited distribution. So the controversy actually resulted in publication of better data. The discussion continued at the 2000 SAE Total Life Cycle Conference in Detroit [19-21].

The arena is ready for a calm, unbiased comparison based on good industry data, as well as for R\&D on more efficient production of materials and new vehicle designs. The analysis should include advanced vehicles (e.g., FreedomCAR), SUVs, and trucks. In the end, a mix of aluminum and light steel parts is likely to be optimum, and novel designs are possible. Other materials (e.g., Mg) could also be included, as discussed in our analysis of potential uses for wrought Mg [22]. The optimum material mix will depend on the decision criteria chosen (e.g., cost, type and quantity of energy use, $\mathrm{CO}_{2}$ ).

\section{CONCLUSIONS}

The experience during six years of operation demonstrated that the AIV was a very practical car with great performance and a fuel economy advantage over a comparable steel-body car. The car proved to be troublefree, and with its high-performance powertrain, it was very popular with users, especially for longer trips. Additional work would be required to quantify the fuel economy benefits of reducing vehicle weight. However, the existence of these benefits is well known in the rail and trucking industries, where reducing vehicle weight allows more freight to be carried, as well as in the automotive industry.

The Al body stood up well and had no rust, rattles, or failures. It was unfortunate in a way that the vehicle was not involved in any significant accidents, so no information was obtained on either repairability or behavior of the vehicle's body under stressed conditions. Conventional vehicles of the same age showed some tendency to rust, but this was not severe. The AIV had many more tiny paint dings, especially on the hood, than did the CVs, and some blistering of the paint, probably resulting from the omission of an E-coat, which would not occur for a mass-produced vehicle. But all of the imperfections were on the surface and very minor; nothing structural or even actually affecting the substrate material was observed. The vehicle looked practically new when we sent it back.

\section{ACKNOWLEDGMENTS}

The authors thank Dr. James J. Eberhardt and Dr. Sidney Diamond, of the Office of Heavy Vehicle Technologies (Office of Transportation Materials, U.S. Department of Energy, when this project was initiated), for their help, support, and valuable guidance. The authors also thank Dan Santini for his thorough review and helpful suggestions. We also thank the owners of the comparison vehicles. And finally, we thank Ford for the opportunity to drive this vehicle. This work was supported by the U.S. Department of Energy, Assistant Secretary for Energy Efficiency and Renewable Energy, Office of Transportation Materials, under contract W-31-109-Eng-38.

\section{REFERENCES}

1. K.R. Brown, et al., The Corrosion Performance of Aluminum Body Panels in Service, SAE980460, International Congress and Exposition, Detroit, MI (February 23-26, 1998)

2. G.J. Courval and J. Allin, After Market Paint Repair of Aluminum Closure Panels, SAE 1999-01-3171, International Body Engineering Conference and Exposition, Detroit, MI (September 28-30, 1999)

3. G.J. Courval and J. Allin, Cosmetic Corrosion of Aluminum Closure Panels: Lab Testing and Field Performance, SAE 2000-01-0064, SAE 2000 World Congress, Detroit, MI (March 6-9, 2000)

4. Stuef, W.C., personal communications, Ford Motor Company, Dearborn, Mich. (1994)

5. Cornille, H., "A High Volume Automotive Body Structure: The Benefits and the Challenges," International Body Engineering Conference, Detroit, Mich. (1993)

6. 1994 Market Data Book, Automotive News (May 25, 1994)

7. R.M. Cuenca, Evaluation of Aluminum Intensive Vehicle - First Year of Operation, ATD-CCM, Dearborn, MI (October 26, 1995)

8. W. Johnston, Ford Advanced Vehicle Group, personal communication (February 2002)

9. D. Santini and J. Anderson, Some Evidence on Determinants of Fuel Economy as a Function of Driving Cycle, SAE 931804, SAE Transactions (1993)

10. National Research Council, Automotive Fuel Economy: How Far Should We Go?, National Academy Press, Washington, D.C. (1992) 
11. D. Santini, A. Vyas, J.L. Anderson, and F. An, Estimating Trade-Offs along the Path to the PNGV $3 X$ Vehicle, Transportation Research Board Annual Meeting, Paper 3222 (January 2001)

12. M. Schuckert, K. Saur, H. Florin, and P. Eyerer, Life Cycle Analysis of Cars - Experience and Results, SAE 1995 Total Life Cycle Conference and Exposition, Vienna, Austria (October 16-19, 1995)

13. Life-Cycle Energy Savings from Aluminum-Intensive Automobiles, F. Stodolsky, R. Cuenca, L. Gaines, and A. Vyas, SAE 1995 Total Life Cycle Conference and Exposition, Vienna, Austria (October 16-19, 1995)

14. Clark, J., Fleet-Based LCA: Comparative $\mathrm{CO}_{2}$ Emission Burden of Aluminum and Steel Fleets, MIT Materials Systems Laboratory (1999)

15. Kirchain, R., M. Hong, F. Field, and J. Clark, Methods for Comparing Product Life Cycles under Temporally Distributed Production Scenarios, Massachusetts Institute of Technology, Executive Summary on web at http://www.autosteel.org/cgi-bin/userlogr (Accessed June 21, 1999)

16. ENN News Environmental News, Study crushes idea for aluminum vehicle, http://www.enn.com/news/ennstories/1999/05/052699/aluminum_3406.asp (accessed May 25, 2001)

17. Roy F. Weston Inc., Life Cycle Inventory Report for the North American Aluminum Industry, The Aluminum Association, Washington, D.C. (November 1998)

18. American Iron and Steel Institute, Life Cycle Inventory Data, received via personal communication with S. Chubbs, Vancouver, BC (1999)

19. K. Martchek, S. Pomper, and J. Green, Credible Life Cycle Inventory Data for Studies of Automotive Aluminum, SAE Paper 2000-01-1497, SAE 2000 Total Life Cycle Conference and Exposition, Detroit, MI (April 26-28, 2000)

20. R. Kirchain, M. Hong, F. Field, and J. Clark, Methods for Comparing Product Life Cycles Under Temporally Distributed Production Scenarios, presentation at SAE 2000 Total Life Cycle Conference and Exposition, Detroit, MI (April 26-28, 2000)

21. P. Peterson, Increased Use of Aluminum in Vehicles: The Environmental Truth, presentation at SAE 2000 Total Life Cycle Conference and Exposition, Detroit, MI (April 26-28, 2000)

22. L. Gaines, R. Cuenca, S. Wu, and F. Stodolsky, Analysis of the Potential for Automotive Uses of Wrought Magnesium, Argonne National Laboratory Report ANL/ESD-35 (February 1997) 